${ }^{1,2}$ Karen Leckie, ${ }^{3}$ Lisi Pilgrem. ${ }^{1}$ University of Cumbria; ${ }^{2}$ St Catherine's Hospice; ${ }^{3}$ Phyllis Tuckwell Hospice Care

\subsection{6/bmjspcare-2016-001245.69}

There is much literature supporting the use of social and therapeutic horticulture (STH) within health and social care settings (King's Fund, 2016). Benefits such as quality of life, well-being, restoration, adjustment and normalisation, affirmation of life and preparation for death through meaningful and valuable activity are deemed as some of the positive elements (Cimprich, 1993; Hartig et al., 2014; King's Fund 2016; Kaplan, 1995).

However, despite these reported benefits, and some limited research relating to gardening in end-of-life care (Unruh, 2000), there remains a dearth of specific research regarding the therapeutic use of gardens and gardening within this field (Cooper Marcus and Sachs, 2014). This may lead to the underutilisation of gardening as a therapeutic occupation.

STH aligns well with providing holistic, person-centred practice, which is key to palliative care (WHO, 2013). Outcomes and evaluation indicate immediate improvement to wellbeing.

Funding for interventions met by voluntary/hospice contributions.

Nature-based and gardening activities, including accessible indoor table-top gardening, have the potential to address complex and multifaceted issues that impact clients affected by lifeshortening illness (Haller and Kramer, 2006).

This subject is timely, as gardening/nature-based interventions are re-gaining popularity within hospice care (e-hospice, 2016).

We aim to:

1. debate both opportunities and challenges of gardening as an occupation for people with life-shortening illness;

2. share some practical examples of STH utilised with clients within palliative care settings;

3. share and discuss development of the STH Model (Pilgrem and Sempik, 2015).

In conclusion, we aim to promote the value of STH as an intervention to be utilised by multi-disciplinary team members (Adevi and Sempik, 2013) to enhance hospice rehabilitative care, which currently has a national profile; 'Enabling people to live fully until they die' (Tiberini and Richardson, 2015).

\section{P-46 "SOW AND GROW", NATURE THAT NURTURES: HORTICULTURAL THERAPY AS PART OF END-OF-LIFE CARE}

Janet Wallis, Rachael Lenon. Martlets Hospice, Hove, UK

\subsection{6/bmjspcare-2016-001245.70}

Introduction Our hospice has provided a horticultural therapy group which is open to in- and out- patients since February 2016. Gardening and being outdoors have well-documented benefits for mental health and general well-being. This group is an example of 'People' within the conference, extending our experience of our patients and volunteers.

Aims The group was formed to help patients spend time with plants and nature. We believe we can reach patients who do not use other services, and provide a relaxed, non-medicalised environment in which patients can support each other. It is patient-led, giving people control of their situation. It is also a setting for emotional support, minor symptom control advice, and identifying patients who need other services or medical follow up.

Methods We hold a weekly two- hour group at the hospice. It is facilitated by a nurse, a horticultural therapist and a volunteer.

We do low-impact activities such as seed sowing and caring for two large raised beds. Patients take plants or produce home or to their bedside. There is time for quiet contemplation, to enjoy the birds, fresh air and the feel of warm soil on their hands.

Results Through patients' reports and observation, we have noticed the benefits of support, advice and sense of well-being. A dying patient who had previously sown cress smelt it and smiled as we held it under her nose. One patient who used to have a garden but now lives in a flat loves being outside again. We have observed peer support and patients taking ownership of the raised beds. Symptom control advice has been given and patients have been referred to our Clinical Nurse Specialists.

Conclusion We plan to review progress at six months.

\section{P-47 ANIMAL ASSISTED THERAPY PROGRAM: A CO-THERAPY} FOR PALLIATIVE CARE

${ }^{1}$ Silvia Carlini. ${ }^{1}$ Maith, Ottiglio, Italy; ${ }^{2}$ Vidas, Milan, Italy; ${ }^{3}$ Palliative Care Federation, Abbiategrasso, Italy

\subsection{6/bmjspcare-2016-001245.71}

In the area of therapy animals, practice is far outpacing research. People think it works and like the idea of it, so they do it.

One challenge as the practice has become more widespread has been explaining how exactly it works. "Positive changes from animal-assisted intervention are varied and there is no single pathway that has yet been identified".

There are a number of theories as to why it works, however.

One is the biophilia hypothesis - essentially that humans have an innate propensity to connect with other living things, another is the social support theory - the idea that therapy animals provide a form of non-judgemental support.

Starting from these statements in 2015, Maith Association has devised a monitoring pattern for hospices together with the hospice staff.

First of all, together with the vet we chose the most ideal animals; while any breed or mutt can be a therapy dog, a certain kind of personality is required. "Visiting unfamiliar people in unfamiliar settings requires a well-trained, healthy dog, with a positive temperament and good manners".

We set goals, mainly recreational and emotional/affectional support:

- fostering patients' mental and physical wellness (for physical wellness we mean try to soothe pain perception)

- emotional support: animals are "emotional intermediary" and further their outing through the non-verbal channel of communication (posture, facial mimicking, body language...)

For a six month period we went to the hospice twice a week and we had access both to atrium and to private bedrooms.

Each therapy session lasted two hours with a break of ten minutes. 